\title{
Novel Therapeutic Agents in Pediatric Sepsis - Zinc
}

\author{
Jeffrey E. Nowak*,1 and Hector R. Wong ${ }^{2}$ \\ ${ }^{I}$ Division of Critical Care Medicine, Cincinnati Children's Hospital Medical Center, The Kindervelt Laboratory for \\ Critical Care Medicine Research, Cincinnati Children's Research Foundation, ${ }^{2}$ Department of Pediatrics, University of \\ Cincinnati College of Medicine, USA
}

\begin{abstract}
Zinc status and infections are closely inter-related. For nearly half a century, the effects that zinc depletion has on the status of the immune system has been slowly elucidated. More recently, the effects that infection and sepsis have on an organism's zinc supplies have begun to be recognized and potential therapeutic intervention in this zinc/infection interplay are beginning to be explored. The literature related to these areas is reviewed, and possible future directions are discussed.
\end{abstract}

Keywords: Zinc, sepsis, immunity, genomics, therapeutics.

\section{INTRODUCTION}

The understanding of the role of zinc in infections and sepsis has been evolving over the past 40-50 years, with interest in the possible therapeutic use of zinc burgeoning in the past decade. Initial clues to the importance of zinc came from clinical deficiency states [1-3]. Subsequently, the important role that zinc plays in a properly functioning immune system has been increasingly recognized, as have many of the mechanistic underpinnings of this relationship [1]. Lastly, recognition of perturbations in zinc status in populations not previously thought to be zinc deficient (including pediatric patients with septic shock) [4] has led to interest in the use of zinc as a therapeutic tool which could be more broadly applied for sepsis.

\section{INFECTIONS IN HUMAN ZINC DEFICIENCY STATES}

Clinical zinc deficiency in humans was first described in 1963 in relation to a syndrome involving iron deficiency anemia, hepatosplenomegally, dwarfism, and hypogonadism [3]. Those who studied this syndrome noted that the subjects suffered from premature death, which appeared to be due to infectious causes, though the investigators lacked the proper facilities in the field to pursue this hypothesis [1].

In the developed world, clinical zinc deficiency is typically recognized only in cases of Acrodermatitis Enteropathica. This condition was initially described in 1942 as a syndrome involving diarrhea, dermatitis, and alopecia [5]. Prior to elucidation of the critical role of zinc in this disorder, reported cases typically died of sepsis [6,7]. In the mid-1970s acrodermatitis enteropathica came to be

\footnotetext{
*Address correspondence to this author at the Division of Critical Care Medicine, Cincinnati Children's Hospital Medical Center, The Kindervelt Laboratory for Critical Care Medicine Research, Cincinnati Children's Research Foundation, USA; Tel: (612) 813-3300; Fax: (612) 813-3349; E-mail: nowak.jeffrey@gmail.com
}

understood as a disorder of zinc deficiency which could be alleviated through oral zinc supplementation [8-11]. Subsequent investigations have revealed that acrodermatitis enteropathica is an autosomal recessive disorder which is due to a defect in the gene coding for the Zip4 transporter protein, leading to impaired intestinal absorption of zinc [12]. With normalization of zinc status, patients have a normal lifespan and no apparent predisposition to sepsis.

Iatrogenic zinc deficiency in humans was created through early formulations of total parenteral nutrition, which were deficient in trace minerals [13]. Likely due to the timely recognition and correction of the underlying zinc deficiency, these patients were not reported to develop sepsis. However, those who were studied during their zinc deficiency were found to have depressed T-cell function, which was reversed with zinc supplementation [14-16].

\section{ROLE OF ZINC IN THE IMMUNE SYSTEM}

The significance of infectious complications in zinc deficiency states has led to considerable research into the role that zinc plays in the immune system. Though much remains to be learned, it is clear that perturbations in zinc concentrations have specific effects on both the innate and adaptive arms of the immune response, as will be discussed below. Additionally, it has recently been shown that zinc

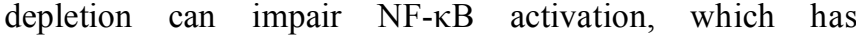
downstream implications for both arms [17].

\section{Zinc and the Innate Immune System}

Zinc status has been shown to affect multiple cells of the innate immune system. Over 25 years ago mild zinc deficiency secondary to hemodialysis was shown to decrease the chemotactic response of neutrophils ex-vivo [18]. Similarly, mild human zinc deficiency has been shown to decrease the number [19] and ex-vivo function [20] of NK cells. From a mechanistic standpoint, it has been shown that 
zinc induces the adhesion of myelomoncytic cells to endothelial cells as well as extracellular matrix proteins, critical steps in chemotaxis [21].

\section{Zinc and the Adaptive Immune System}

Zinc deficiency in humans or rodents leads to lymphopenia through increased apoptosis of pre-B and pre-T cells, with mature $\mathrm{B}$ and $\mathrm{T}$ cells being relatively resistant [22]. This lymphopenia causes the organism as a whole to display impaired antibody production $[23,24]$ however, the B cells that remain do not show decreased antibody production on a per cell basis [24].

Zinc has multiple effects on T-cell function. On a gross level, zinc deficiency results in thymic atrophy, which is reversible with supplementation [25]. Further, zinc is an essential cofactor for thymulin, a hormone which has multiple effects, including: regulation of immature T-cell differentiation in the thymus; induction of proliferation of CD8+ T-cells; and promotion of T-cell function [1,26]. Even mild zinc depletion in humans has been shown to decrease thymulin activity, which was subsequently restored with supplementation [27]. Finally, zinc deficiency leads to an alteration of the Th1:Th2 balance through decreases in the Th1 cytokines [28].

\section{HUMAN ZINC SUPPLEMENTATION}

Depressed zinc levels are found in multiple populations of patients who have an increased susceptibility to infections, including (but not limited to) patients with trisomy 21 [29], hemoglobin SS [30], Acquired Immunodeficiency Syndrome [31], hepatic cirrhosis [32], and the elderly [33]. Trials of oral zinc supplementation in each these populations have demonstrated improvement in markers of immune function [29,31-35]. Additionally, zinc supplementation has produced a decrease in the incidence of infection in all of these populations (except those with cirrhosis, who were not studied for this endpoint), even leading to a decrease in hospitalizations among patients with hemoglobin SS [30,31,36,37].

Children in developing countries are at risk of trace element deficiency. Noting that deficiency in zinc may worsen diarrheal illness and susceptibility to infections, members of the Department of International Health at John's Hopkins have partnered with agencies in these countries to study the effect of oral zinc supplementation in large numbers of at risk children. Indian children from 6-35 months of age who presented with acute diarrhea and were supplemented with $20 \mathrm{mg}$ of elemental zinc daily had decreased severity and duration of diarrhea compared with children who received placebo [38]. Once the children in this study had resolution of their diarrheal illness, their dose of zinc (or placebo) was halved, and they were followed for an additional six months to assess the burden of acute lower respiratory infections. Daily oral supplementation of $10 \mathrm{mg}$ of elemental zinc decreased both the incidence (by $45 \%$ ) and the prevalence (by 40\%) of acute lower respiratory tract infections in this population [39]. A separate study of over 42,000 children aged 1-48 months in Zanzibar to evaluate the effect of prophylactic zinc (vs. placebo) on mortality showed a non-significant trend toward decreased mortality in the zinc supplementation group as a whole (relative risk
$0.93 ; \mathrm{p}=0.294)$ [40]. An a priori planned subgroup analysis of these data showed a significant reduction of the mortality rate for children aged 12-48 months who received zinc supplementation (relative risk $0.82 ; \mathrm{p}=0.045$ ), which was driven primarily by a decrease in infection-related deaths [40].

\section{ZINC IN SEPSIS AND CRITICAL ILLNESS}

Modern computing and microarray genomic expression technology allow for the collection and analysis of vast amounts of data. This makes possible the design of hypothesis-generating studies and the resultant discovery of unexpected findings, which may have been missed with targeted, hypothesis-driven studies. The Genomics in Pediatric SIRS/Septic Shock Investigators have developed a multi-site study of the genomic response to septic shock, sepsis, or the systemic inflammatory response syndrome (SIRS) in the pediatric population which utilizes this hypothesis-generating strategy. Initial data from this study revealed that pediatric septic shock is associated with widespread downregulation of the expression of genes related to zinc and metal binding [4]. This repression pattern has subsequently been validated in a separate cohort of pediatric patients with septic shock [41], and has been shown to persist through at least day three of illness [42]. The most recent analysis shows that this repression pattern is not seen in pediatric patients with SIRS or sepsis, rather, it appears to be specific for patients with septic shock [43].

In addition to the downregulation of zinc related genes in pediatric septic shock patients, the population of patients who subsequently died displayed an upregulation of two isoforms of metallothionein, when compared with patients who survived the episode of septic shock [4]. This is noteworthy, as metallothioneins can bind and sequester zinc intracellularly, and thus their upregulation could lead to a decrease in the serum levels and bioavailability of zinc.

These data were then followed up with further, hypothesis-driven investigation. Measurement of serum zinc levels showed that these levels were normal in the population of children who survived their septic shock, whereas they were significantly lower in those children who subsequently died [4]. Additionally, a study done using metallothionein-null mice showed that these mice had a survival advantage following polymicrobial sepsis, when compared with wild-type controls [4]. This suggests that the upregulation of metallothionein isoforms seen in children who died of septic shock is, in fact, maladaptive.

Induction of sepsis in animal models allows for more controlled study of the interaction between zinc status and response to sepsis. Diet-induced sub-acute zinc deficiency in mice has been shown to increase mortality from sepsis resulting from either parasitemia [44] or polymicrobial intraabdominal infection [45]. The zinc-deficient mice subjected to polymicrobial sepsis displayed increased production of pro-inflammatory cytokines and increased tissue damage in their lungs and spleens, when compared to control mice subjected to the same insult [45]. Mice who were made zincdeficient for 3 weeks, but then had their zinc levels repleted in the 3 days preceding infection had cytokine levels and tissue damage similar to control mice, however, their survival rate was in between that of the control and zinc 
deficient mice [45]. This suggests that the survival disadvantage conferred by zinc deficiency likely results from a combination of both the acute response to infection (such as increased inflammation and decreased anti-oxidant capacity) and the longer-term sequellae of zinc deficiency (such as lymphopenia or alterations of the genome expression pattern).

To date, no human studies of zinc supplementation in patients with sepsis have been published, however, data regarding zinc supplementation in patients with critical illness are available. Heyland et. al. recently published a meta-analysis of randomized clinical trials of zinc supplementation in mechanically ventilated, critically ill adults [46]. Four studies-consisting of trauma and large $(>20 \%$ body surface area) burns - met their criteria. Their analysis indicated that zinc supplemented patients had a trend toward decreased mortality (relative risk $=0.63$ ), however, the sample size and variability precluded statistical significance $(p=0.33)$ [46]. In a separate, single-center study of antioxidant and glutamine supplementation of mechanically ventilated, hypoperfused adults Heyland et. al. provided varying levels of enteral zinc supplementation, either none $(\mathrm{n}=7), 10 \mathrm{mg}(\mathrm{n}=7)$, or $20 \mathrm{mg}(\mathrm{n}=14)$ of elemental zinc per day [47]. Neither of the supplemental doses restored normal zinc levels in these patients, but they did result in a trend toward increased serum zinc levels, whereas the group which received no supplemental zinc had a decrease in their serum zinc levels [46]. Further, analysis of zinc levels over time revealed that survivors had an increase in their zinc levels over time, which was significantly different from nonsurvivors, whose zinc levels did not increase [46].

\section{FUTURE DIRECTIONS}

Given the biological underpinnings, and the preliminary data in critically ill patients, a logical next step is a randomized, controlled trial of zinc supplementation in patients with sepsis and/or septic shock. When considering or conducting such a study, one must be open to the fact that the alterations seen in zinc status may be adaptivetherefore, zinc supplementation may lead to a worse outcome. There is some in-vitro evidence which suggests that zinc may enhance bacterial virulence [48], and clinical experience with iron demonstrates the complexity involved in predicting the response to therapeutic manipulation of trace element status in the face of infections. Chelation of iron has been shown to improve outcome in children with cerebral malaria [49]. Also, the oral supplementation trial in Zanzibar referenced earlier initially included arms containing iron and folic acid supplementation which were stopped early due to an increase in the rate of hospitalization or death [50]. The important difference between supplementation of iron and zinc is highlighted by the fact that (as mentioned above) this same trial in Zanzibar showed that zinc supplementation lead to decreased mortality [40]. Likewise, iron supplementation has been reported to increase mortality in a murine model of polymicrobial sepsis [51], whereas preliminary data from our laboratory indicate that zinc supplementation decreases mortality in such a model. Furthermore, the survival benefit seen in metallothioneinnull mice and the decreased serum zinc levels in pediatric patients who died from septic shock relative to those who survived septic shock both indicate that the lowered plasma zinc levels seen in these patients are not likely due to an adaptive response [4]. Taking into account all of the available evidence, a therapeutic trial appears to be warranted.

Questions regarding a possible study that need to be addressed are the proper route, dose, and duration of therapy. For the sake of reliability, the intravenous route should be the preferred method of zinc delivery, given the variable bioavailability of zinc when it is provided enterally [52]. Determining the proper dose and duration of zinc supplementation is more difficult. Two studies indicate that $20 \mathrm{mg}$ of elemental zinc per day provided enterally to critically ill adults $(300 \mathrm{mcg} / \mathrm{kg} /$ day assuming a typical adult weight of $70 \mathrm{~kg}$ ) does not consistently restore plasma zinc levels to normal [46,53]. Similarly, intravenous supplementation of severely burned adults with $37.5 \mathrm{mg}$ of elemental zinc per day $(540 \mathrm{mcg} / \mathrm{kg} / \mathrm{d})$ for 8 days following severe burns resulted in a somewhat less pronounced serum zinc deficiency than that of control patients, but did not hasten the return to normal zinc levels, which occurred on post-burn day 20 in both groups [54]. Thus, it appears that supplementation should be done with doses greater than 600 $\mathrm{mcg} / \mathrm{kg} / \mathrm{day}$; however, some caution must be exercised, as high concentrations of zinc could depress immune function. In vitro, high concentrations of zinc have been shown to decrease T-cell proliferation through inhibition of IL-1 receptor-associated protein kinase [55]. A dose of 300 $\mathrm{mg} /$ day $(4,300 \mathrm{mcg} / \mathrm{kg} /$ day $)$ given enterally to healthy adult males for 42 days caused a decrease in ex-vivo neutrophil chemotaxis and phagocytosis [56]; and a dose of 1,900 $\mathrm{mcg} / \mathrm{kg} / \mathrm{day}$ ( $\pm 300 \mathrm{mcg} / \mathrm{kg} /$ day) given enterally to infants recovering from marasmus impaired phagocytosis and fungicidal activity in ex-vivo monocytes after 60 and 105 days of supplementation, respectively [57]. It is noteworthy that both of these studies showing decreased ex-vivo immune function studied the effects of relatively long-term supplementation, and that the study of marasmic infants was also purported to show that zinc supplementation resulted in improvement of other measures of immune function (delayed hypersensitivity skin reactions, lymphoproliferative response to phytohemagglutinin, and salivary IgA concentrations), as well as improvement of linear growth [58]. In contrast to these long-term supplementation experiments, a study of $150 \mathrm{mg} /$ day $(2,140 \mathrm{mcg} / \mathrm{kg} /$ day $)$ of elemental zinc given enterally to severely burned adults demonstrated a decreased time to wound healing without any adverse effects (though no ex-vivo studies were done) [59]. When taking into account all of the above, along with preliminary data from our lab regarding parenteral supplementation of zinc in mice subjected to polymicrobial sepsis, we believe that a reasonable zinc supplementation regimen would be a dose in the range of $1,000-2,000$ $\mathrm{mcg} / \mathrm{kg} /$ day of elemental zinc administered intravenously for 7 to 10 days.

\section{CONCLUSIONS}

The understanding of zinc metabolism and its role in a properly functioning immune system has increased steadily throughout the past 50 years. It is clear that zinc plays a pivotal role in the immune response, and that perturbations in zinc status adversely impact outcome following infection. 
Hopefully, we will soon be able to leverage this increased understanding into therapeutic interventions which will improve the outcome of pediatric sepsis.

\section{REFERENCES}

[1] Prasad AS. Zinc in human health: effect of zinc on immune cells. Mol Med 2008; 14: 353-7.

[2] Halsted JA, Prasad AS. Syndrome of iron deficiency anemia, hepatosplenomegaly, hypogonadism, dwarfism and geophagia. Trans Am Clin Climatol Assoc 1960; 72: 130-49.

[3] Prasad AS, Miale A, Farid Z, Sandstead HH, Schulert AR. Clinical and experimental. Zinc metabolism in patients with the syndrome of iron deficiency anemia, hepatosplenomegaly, dwarfism, and hypogonadism. J Lab Clin Med 1990; 116: 737-49.

[4] Wong HR, Shanley TP, Sakthivel B, et al. Genome-level expression profiles in pediatric septic shock indicate a role for altered zinc homeostasis in poor outcome. Physiol Genomics 2007; 30: $146-55$.

[5] Danbolt N, Closs K. Acrodermatitis enteropathica. Acta Derm Venereol 1942; 23: 127.

[6] Margileth AM. Acrodermatitis enteropathica. Case report and review of literature. Am J Dis Child 1963; 105: 285-91.

[7] Julius R, Schulkind M, Sprinkle T, Rennert O. Acrodermatitis enteropathica with immune deficiency. J Pediatr 1973; 83: 100711 .

[8] Barnes PM, Moynahan EJ. Zinc deficiency in acrodermatitis enteropathica: multiple dietary intolerance treated with synthetic diet. Proc R Soc Med 1973; 66: 327-9.

[9] Moynahan EJ. Letter: acrodermatitis enteropathica: a lethal inherited human zinc-deficiency disorder. Lancet 1974; 2: 399-400.

[10] Neldner KH, Hambidge KM. Zinc therapy of acrodermatitis enteropathica. N Engl J Med 1975; 292: 879-82.

[11] Walravens PA, Hambidge KM, Neldner $\mathrm{KH}$, et al. Zinc metabolism in acrodermatitis enteropathica. J Pediatr 1978; 93: 713.

[12] Maverakis E, Fung MA, Lynch PJ, et al. Acrodermatitis enteropathica and an overview of zinc metabolism. J Am Acad Dermatol 2007; 56: 116-24.

[13] Kay RG, Tasman-Jones C. Acute zinc deficency in man during intravenous alimentation. Aust N Z J Surg 1975; 45: 325-30.

[14] Oleske JM, Westphal ML, Shore S, Gorden D, Bogden JD, Nahmias A. Zinc therapy of depressed cellular immunity in acrodermatitis enteropathica. Its correction. Am J Dis Child 1979; 133: 915-8.

[15] Mozzillo N, Ayala F, Formato A, Forestieri P, Mazzeo F. First full blown syndrome of acute zinc deficiency in course of long term total parenteral nutrition: a clinical case. Ital J Surg Sci 1984; 14: 229-31.

[16] Allen JI, Kay NE, McClain CJ. Severe zinc deficiency in humans: association with a reversible T-lymphocyte dysfunction. Ann Intern Med 1981; 95: 154-7.

[17] Prasad AS, Bao B, Beck FW, Sarkar FH. Zinc activates NF-kappaB in HUT-78 cells. J Lab Clin Med 2001; 138: 250-6.

[18] Briggs WA, Pedersen MM, Mahajan SK, Sillix DH, Prasad AS, McDonald FD. Lymphocyte and granulocyte function in zinctreated and zinc-deficient hemodialysis patients. Kidney Int 1982; 21: 827-32.

[19] Ravaglia G, Forti P, Maioli F, et al. Effect of micronutrient status on natural killer cell immune function in healthy free-living subjects aged $>/=90$ y. Am J Clin Nutr 2000; 71: 590-8.

[20] Allen JI, Perri RT, McClain CJ, Kay NE. Alterations in human natural killer cell activity and monocyte cytotoxicity induced by zinc deficiency. J Lab Clin Med 1983; 102: 577-89.

[21] Chavakis T, May AE, Preissner KT, Kanse SM. Molecular mechanisms of zinc-dependent leukocyte adhesion involving the urokinase receptor and beta2-integrins. Blood 1999; 93: 2976-83.

[22] Fraker PJ, King LE. Reprogramming of the immune system during zinc deficiency. Annu Rev Nutr 2004; 24: 277-98.

[23] DePasquale-Jardieu P, Fraker PJ. Interference in the development of a secondary immune response in mice by zinc deprivation: persistence of effects. J Nutr 1984; 114: 1762-9.

[24] Cook-Mills JM, Fraker PJ. Functional capacity of the residual lymphocytes from zinc-deficient adult mice. Br J Nutr 1993; 69: 835-48.
[25] Mocchegiani E, Santarelli L, Muzzioli M, Fabris N. Reversibility of the thymic involution and of age-related peripheral immune dysfunctions by zinc supplementation in old mice. Int $\mathrm{J}$ Immunopharmacol 1995; 17: 703-18.

[26] Ibs K, Rink L. Zinc-altered immune function. J Nutr 2003; $133(5$ Suppl 1): 1452S-6S.

[27] Prasad AS, Meftah S, Abdallah J, et al. Serum thymulin in human zinc deficiency. J Clin Invest 1988; 82: 1202-10.

[28] Prasad AS. Effects of zinc deficiency on Th1 and Th2 cytokine shifts. J Infect Dis 2000; 182 (Suppl 1): S62-8.

[29] Björkstén B, Bäck O, Gustavson KH, Hallmans G, Hägglöf B, Tärnvik A. Zinc and immune function in Down's syndrome. Acta Paediatr Scand 1980; 69: 183-7.

[30] Prasad AS, Beck FW, Kaplan J, et al. Effect of zinc supplementation on incidence of infections and hospital admissions in sickle cell disease (SCD). Am J Hematol 1999; 61: 194-202.

[31] Mocchegiani E, Veccia S, Ancarani F, Scalise G, Fabris N. Benefit of oral zinc supplementation as an adjunct to zidovudine (AZT) therapy against opportunistic infections in AIDS. Int $\mathbf{J}$ Immunopharmacol 1995; 17: 719-27.

[32] Labadie H, Verneau A, Trinchet JC, Beaugrand M. [Does oral zinc improve the cellular immunity of patients with alcoholic cirrhosis?]. Gastroenterol Clin Biol 1986; 10: 799-803.

[33] Prasad AS, Fitzgerald JT, Hess JW, Kaplan J, Pelen F, Dardenne M. Zinc deficiency in elderly patients. Nutrition 1993; 9: 218-24.

[34] Abdallah JM, Kukuruga M, Nakeff A, Prasad AS. Cell cycle distribution defect in PHA-stimulated T lymphocytes of sickle cell disease patients. Am J Hematol 1988; 28: 279-81.

[35] Cakman I, Kirchner H, Rink L. Zinc supplementation reconstitutes the production of interferon-alpha by leukocytes from elderly persons. J Interferon Cytokine Res 1997; 17(8): 469-72.

[36] Licastro F, Chiricolo M, Mocchegiani E, et al. Oral zinc supplementation in Down's syndrome subjects decreased infections and normalized some humoral and cellular immune parameters. J Intellect Disabil Res 1994; 38 ( Pt 2): 149-62.

[37] Prasad AS, Beck FWJ, Bao B, et al. Zinc supplementation decreases incidence of infections in the elderly: effect of zinc on generation of cytokines and oxidative stress. Am J Clin Nutr 2007; 85: 837-44

[38] Sazawal S, Black RE, Bhan MK, Bhandari N, Sinha A, Jalla S. Zinc supplementation in young children with acute diarrhea in India. N Engl J Med 1995 28; 333: 839-44.

[39] Sazawal S, Black RE, Jalla S, Mazumdar S, Sinha A, Bhan MK. Zinc supplementation reduces the incidence of acute lower respiratory infections in infants and preschool children: a doubleblind, controlled trial. Pediatrics 1998; 102(1 Pt 1): 1-5.

[40] Sazawal S, Black RE, Ramsan M, et al. Effect of zinc supplementation on mortality in children aged 1-48 months: a community-based randomised placebo-controlled trial. Lancet 2007; 369: 927-34.

[41] Cvijanovich N, Shanley TP, Lin R, et al. Validating the genomic signature of pediatric septic shock. Physiol Genomics 2008; 34: 127-34.

[42] Shanley TP, Cvijanovich N, Lin R, et al. Genome-level longitudinal expression of signaling pathways and gene networks in pediatric septic shock. Mol Med 2007; 13: 495-508.

[43] Wong HR, Cvijanovich N, Allen GL, et al. Genomic expression profiling across the pediatric systemic inflammatory response syndrome, sepsis, and septic shock spectrum. Crit Care Med 2009; 37: $1558-66$

[44] Fraker PJ, Caruso R, Kierszenbaum F. Alteration of the immune and nutritional status of mice by synergy between zinc deficiency and infection with Trypanosoma cruzi. J Nutr 1982; 112: 1224-9.

[45] Knoell DL, Julian MW, Bao S, et al. Zinc deficiency increases organ damage and mortality in a murine model of polymicrobial sepsis. Crit Care Med 2009; 37: 1380-8.

[46] Heyland DK, Jones N, Cvijanovich NZ, Wong H. Zinc supplementation in critically ill patients: a key pharmaconutrient? JPEN J Parenter Enteral Nutr 2008; 32: 509-19.

[47] Heyland DK, Dhaliwalm R, Day A, Drover J, Cote H, Wischmeyer P. Optimizing the dose of glutamine dipeptides and antioxidants in critically ill patients: a phase I dose-finding study. JPEN J Parenter Enteral Nutr 2007; 31: 109-18.

[48] Sugarman B, Epps LR, Stenback WA. Zinc and bacterial adherence. Infect Immun 1982; 37: 1191-9. 
[49] Gordeuk V, Thuma P, Brittenham G, et al. Effect of iron chelation therapy on recovery from deep coma in children with cerebral malaria. N Engl J Med 1992; 327: 1473-7.

[50] Sazawal S, Black RE, Ramsan M, et al. Effects of routine prophylactic supplementation with iron and folic acid on admission to hospital and mortality in preschool children in a high malaria transmission setting: community-based, randomised, placebocontrolled trial. Lancet 2006; 367: 133-43.

[51] Javadi P, Buchman TG, Stromberg PE, et al. High-dose exogenous iron following cecal ligation and puncture increases mortality rate in mice and is associated with an increase in gut epithelial and splenic apoptosis. Crit Care Med 2004; 32: 1178-85.

[52] Lönnerdal B. Dietary factors influencing zinc absorption. J Nutr 2000; 130: 1378S-83S.

[53] Beale RJ, Sherry T, Lei K, et al. Early enteral supplementation with key pharmaconutrients improves Sequential Organ Failure Assessment score in critically ill patients with sepsis: outcome of a randomized, controlled, double-blind trial. Crit Care Med 2008; 36: $131-44$.
[54] Berger MM, Spertini F, Shenkin A, et al. Trace element supplementation modulates pulmonary infection rates after major burns: a double-blind, placebo-controlled trial. Am J Clin Nutr 1998; 68: 365-71.

[55] Wellinghausen N, Martin M, Rink L. Zinc inhibits interleukin-1dependent T cell stimulation. Eur J Immunol 1997; 27: 2529-35.

[56] Chandra RK. Excessive intake of zinc impairs immune responses. JAMA 1984; 252: 1443-6.

[57] Schlesinger L, Arevalo M, Arredondo S, Lönnerdal B, Stekel A. Zinc supplementation impairs monocyte function. Acta Paediatr 1993; 82: 734-738.

[58] Schlesinger L, Arevalo M, Arredondo S, Diaz M, Lönnerdal B, Stekel A. Effect of a zinc-fortified formula on immunocompetence and growth of malnourished infants. Am J Clin Nutr 1992; 56: 4918.

[59] Han CM. [Changes in body zinc and copper levels in severely burned patients and the effects of oral administration of $\mathrm{ZnSO} 4$ by a double-blind method--in Chinese; English abstract]. Zhonghua Zheng Xing Shao Shang Wai Ke Za Zhi. 1990; 6: 83-86.

(C) Nowak and Wong; Licensee Bentham Open.

This is an open access article licensed under the terms of the Creative Commons Attribution Non-Commercial License (http://creativecommons.org/licenses/by-nc/3.0/) which permits unrestricted, non-commercial use, distribution and reproduction in any medium, provided the work is properly cited. 